\title{
Nonpharmacological Management of Gastroesophageal Reflux in Preterm Infants
}

\author{
Luigi Corvaglia, ${ }^{1,2}$ Silvia Martini, ${ }^{1}$ Arianna Aceti, ${ }^{1}$ Santo Arcuri, ${ }^{1,2}$ \\ Roberto Rossini, ${ }^{1,2}$ and Giacomo Faldella ${ }^{1,2}$ \\ ${ }^{1}$ Neonatology and Neonatal Intensive Care Unit, S. Orsola-Malpighi Hospital, Via Massarenti 11, 40138 Bologna, Italy \\ ${ }^{2}$ Department of Medical and Surgical Sciences (DIMEC), University of Bologna, Via Massarenti 9, 40138 Bologna, Italy
}

Correspondence should be addressed to Luigi Corvaglia; luigi.corvaglia@unibo.it

Received 29 April 2013; Accepted 25 July 2013

Academic Editor: Jonathan Muraskas

Copyright (C) 2013 Luigi Corvaglia et al. This is an open access article distributed under the Creative Commons Attribution License, which permits unrestricted use, distribution, and reproduction in any medium, provided the original work is properly cited.

Gastroesophageal reflux (GOR) is very common among preterm infants, due to several physiological mechanisms. Although GOR should not be usually considered a pathological condition, its therapeutic management still represents a controversial issue among neonatologists; pharmacological overtreatment, often unuseful and potentially harmful, is increasingly widespread. Hence, a stepwise approach, firstly promoting conservative strategies such as body positioning, milk thickening, or changes of feeding modalities, should be considered the most advisable choice in preterm infants with GOR. This review focuses on the conservative management of GOR in the preterm population, aiming to provide a complete overview, based on currently available evidence, on potential benefits and adverse effects of nonpharmacological measures. Nonpharmacological management of GOR might represent a useful tool for neonatologists to reduce the use of antireflux medications, which should be limited to selected cases of symptomatic babies.

\section{Introduction}

Gastroesophageal reflux (GOR) is common in preterm infants, with a $22 \%$ estimated incidence in babies born before 34 weeks of gestation [1]. Several factors may contribute to its development: relatively abundant milk intakes, the supine posture which promotes the passage of liquid gastric content into oesophagus, the immature oesophageal motility, and the subsequent poor oesophageal clearance of refluxate [2]. Hence, in the preterm population GOR is due to several physiological mechanisms, and it should not be usually considered as pathological. However, in moderate to severe cases, GOR may lead to complications, such as lung aspiration, esophagitis, feeding problems, and failure to thrive [3], therefore prolonging hospital stay [4]; its linkage with apnoeas [5] or chronic lung disease [6-8] is still on debate.

The therapeutic management of GOR still represents a controversial issue among neonatologists. A stepwise approach, promoting at first nonpharmacological interventions such as body positioning, milk thickening, or modifications in feeding modalities, should be considered the most advisable choice to manage GOR in preterm infants [3, $5,9]$; this would allow avoiding pharmacological treatment, which could be limited to those infants who do not benefit from conservative measures or who experience GOR clinical complications [10].

In recent years, however, the empiric use of antireflux medications, both during hospital stay in Neonatal Intensive Care Unit (NICU) and after discharge [11], has substantially increased. Pharmacological therapies have been shown to increase the risk of serious adverse effects in the neonatal population: the use of gastric acid inhibitors, that is, histamine-2 (H2) blockers and proton pump inhibitors (PPI), has been recently linked to increased rates of necrotizing enterocolitis (NEC) $[12,13]$ and infections (overall infections, sepsis, pneumonia, and urinary tract infections) [14], whereas cisapride administration was proven to provoke a relevant prolongation of QTc $[15,16]$.

Specific diagnostic investigations should be performed before treatment, in order to assess GOR features, because the prevalence of acid or nonacid GORs has different clinical and therapeutic implications. Specifically, acid reflux, which 
occurs predominantly in the late postprandial period [17], is reported to play a relevant role in the development of gastroesophageal reflux disease (GORD) [2], whereas nonacid reflux, which is more frequent during the early postprandial period [17], has been proposed as a potential trigger for GORrelated apnoeas in the preterm population [18]. It should be also considered that many pharmacological therapies act specifically on acid GOR, while different conservative strategies have different effects on acid and nonacid GORs.

Due to its ability to both detect acid, weakly acid, and alkaline GORs [17] and assess the physical nature (gaseous, liquid, or mixed) of reflux episodes, combined multiple intraluminal impedance (MII) and $\mathrm{pH}$ monitoring is highly effective in detailing GOR features, being superior to $\mathrm{pH}-$ metry and MII alone. It is currently considered the best choice to diagnose GOR $[3,19]$ and to evaluate the efficacy of antireflux therapy [20]. Additionally, a reflux scoring system based on clinical observation and suited for hospitalized preterm infants has been recently developed for GOR diagnosis and management [3]; this questionnaire, however, cannot replace standard diagnostic investigations and needs further validation.

This review focuses on conservative management of GOR in preterm infants, aiming to provide a complete overview on potential benefits and adverse effects of currently available nonpharmacological measures.

\section{Body Positioning}

Body positioning is widely used as a conservative approach to manage GOR in hospitalized preterm infants [1]. Since 1982, when a decrease of GOR was noted in prone neonates [21], several trials tested the efficacy of different body positions on GOR indexes in both term and preterm infants.

The first study on preterm infants dates back to 1999 , when Ewer et al. [22] found a relevant improvement in acid reflux indexes (frequency, reflux index, number of refluxes longer than 5 minutes, and duration of the longest episode) at $\mathrm{pH}$ monitoring in both prone and left-side positions. The effectiveness of prone position was later confirmed by Bhat et al. [23], who examined by means of $\mathrm{pH}$ monitoring a cohort of healthy preterm infants before discharge. Omari et al. [24] combined oesophageal manometry and MII to investigate the efficacy of left versus right lateral position on GOR features in healthy preterm infants; left-side positioning resulted in a significant decrease of transient lower oesophageal sphincter relaxations (TLOSRs), which are known to be the main triggering mechanisms for GOR episodes, whereas right lateral position was associated with a higher number of TLOSRs and liquid refluxes [25].

While $\mathrm{pH}$ monitoring is not effective in detecting nonacid GORs, MII alone cannot distinguish between acid and nonacid refluxes; hence, we assessed the effects of body positioning on both acid and nonacid GORs in preterm symptomatic infants combining $\mathrm{MII}$ and $\mathrm{pH}$ monitoring (pH-MII) [26]. Lower acid and nonacid GOR indexes were observed in both prone and left lateral positions. Particularly, left-side positioning led to a significant decrease of acid GOR episodes during the earlier postprandial period (up to 1 hour and 30 minutes after meal), while the prone posture was more effective to reduce acidic oesophageal exposure in the late postprandial period.

In conclusion, body positioning can be considered an effective strategy to manage both acid and nonacid GORs in preterm infants; improvements of GOR indexes are observed in prone and left lateral positions, whereas supine and right lateral positioning seem to play a worsening effect. However, due to the established risk of sudden infant death syndrome (SIDS) linked to prone positioning [27], this measure is limited to hospitalized babies and should not be applied in symptomatic infants discharged without cardiorespiratory monitoring.

Placing the babies on a head-up slope is a measure frequently adopted in clinical practice [1]. However, head elevation resulted to be ineffective to reduce acid GOR in both prone and supine positions [28, 29]; furthermore, the car seat positioning was found to elicit acid GOR exacerbations [30]. Data on preterm infants, however, are currently lacking. Hence, on the basis of the available evidence, head rising should not be considered an effective strategy to reduce GOR in term infants up to six months of life.

\section{Feeding Strategies}

Feeds frequency (every two, three, or four hours), as well as different feeding modalities, are thought to influence GOR features.

The relationship between feeds frequency and GOR episodes in both term and preterm infants was investigated at first by Omari et al. [2], who observed a positive correlation between the frequency of feedings and the occurrence of nonacid GOR episodes, with a concomitant decrease in the number of acid GOR, which is known to be determinant for the development of GORD [31]. According to the results of this study, it can be hypothesised that frequent, smallvolume feeds probably reduce GOR in mildly symptomatic infants with prolonged oesophageal acid exposure but have no benefit for symptomatic babies with predominant nonacid GOR.

Bolus and continuous tube feedings are the most common enteral feeding techniques in NICUs. Clinical practice suggests that changing the feeding method (i.e., shifting from bolus to continuous feeding or vice versa) may represent an effective conservative approach in neonates with symptomatic GOR [3]. Indeed, the permanence of a tube through lower oesophageal sphincter (LOS) is shown to affect the occurrence of GOR [32], while the sudden gastric distension determined by bolus administration can impair LOS continence, thus favouring GOR $[5,33,34]$.

The effect of different feeding strategies on GOR in a preterm cohort has been recently assessed by Jadcherla et al. [35] by means of pH-MII. A significant negative correlation between feeding duration and total GOR events, number of nonacid GORs, and time of oesophageal bolus clearance was observed. Consistently with this finding, lowered feeding flow rates $(\mathrm{mL} / \mathrm{min})$ yielded a decrease in the same GOR 
features. Thus, the reduction of feeding flow rate, which results in a prolonged feeding duration, seems to represent a potentially useful strategy for GOR management, especially in those infants with predominant nonacid GOR. However, further trials are needed to confirm these preliminary data.

\section{Feed Thickening}

Thickened feeds, that is, human milk or formula added with thickening agents or commercial antiregurgitation (AR) formulas, are increasingly being used as nonpharmacological treatments of GOR in symptomatic infants [1].

In 2008, Horvath et al. systematically evaluated data from randomized controlled trials performed in term infants on the efficacy of thickened formulas on GOR features, detected with $\mathrm{pH}$ monitoring. Despite a significant decrease of symptoms as regurgitations and vomiting and an increase in daily weight gain, thickening agents were ineffective in reducing acid GOR indexes [36]. An improvement of acid GOR features in infants fed a corn starch thickened formula has been reported in only one trial [37]. As for nonacid GOR, a remarkable reduction of reflux episodes, mean oesophageal reflux height, and frequency of regurgitation was observed by Wenzl et al. in association with the use of a galactomannanthickened formula [38].

Further investigations in larger controlled trials are needed in order to investigate the safety profile of thickening agents. So far, an increase in coughing was noticed in symptomatic babies fed on rice-thickened formulas [39], and a case of an allergic reaction linked with carob gum thickening has been described [40]. Moreover, despite that infants fed formulas thickened with indigestible carbohydrate showed normal growth and nutritional parameters at a 3-month follow-up study [41], the use of carob bean gum, evaluated in vitro, was reported to affect the intestinal absorption of calcium, iron, and zinc more than thickening with digestible carbohydrates [42].

With regard to the preterm population, only a small number of studies on the effectiveness and the safety of thickening agents are currently available. We have previously investigated the efficacy of fortified human milk thickened with precooked starch in a small cohort of preterm symptomatic infants: no improvement in the rates of both acid and nonacid GORs was documented; additionally, a trend toward an increase of the total number of GORs was observed. To the best of our knowledge, this was the first study testing the effectiveness of thickened human milk in preterm infants; on the basis of these preliminary results, starch-thickening of fortified human milk does not appear to be an advisable strategy to reduce GOR in preterm symptomatic infants [43]. Furthermore, a linkage between milk thickening and NEC development has been recently suggested [44, 45]; hence, milk thickening in the preterm population is not recommended before an adequate achievement of feeding tolerance [3].

Commercial thickened formulas are inadequate for the nutritional needs of preterm infants, due to their lower caloric and protein contents and to the lack of long-chain polyunsaturated fatty acids (LCPUFA), which play a relevant role in the structural development of retinal membranes and central nervous system (CNS). In our previous study, a starchthickened formula tailored on preterms nutritional needs was specifically designed to investigate its efficacy on GOR features in symptomatic preterm infants [46]. The thickened formula, however, was found to be ineffective on nonacid GOR features, evaluated by means of combined pH-MII. This result might be explained by the properties of the amylopectin component, which increases its viscosity at an acid gastric $\mathrm{pH}$, being thereby effective during the late postprandial period, when nonacid GOR does not prevail [17]. Despite the significantly lowered rate of acid GORs, the thickened formula failed to reduce the mean oesophageal acid exposure, which is known to be the main determinant index for the development of GORD [31]. Moreover, when compared to a standard preterm formula, this thickened formula yielded a longer duration of acid GOR episodes, which was probably due to a slower oesophageal clearance. There are no data on the safety of thickened formulas in preterm infants. Hence, as well as human milk thickening, formula thickening seems to be ineffective to reduce GOR in symptomatic preterm infants. Nevertheless, larger controlled trials might be advisable to confirm these preliminary findings and to assess the safety of thickened formulas in the preterm population.

\section{Hydrolysed Formulas}

Hydrolysed protein formulas (HPFs) are reported to reduce gastrointestinal transit time [47], to increase stool frequency [48], and to improve feeding tolerance, therefore leading to an earlier achievement of full enteral feeding [49]. Several mechanisms through which HPFs could act have been proposed [50]; whereas some evidence suggests that HPFs elicit a higher motilin release than standard preterm formulas (SPFs) [51], a study performed on animals has shown that protein hydrolysis diminishes the activity of milk protein-derived opioid receptor agonists ( $\beta$-casomorphins) [52]. The effect of HPFs on gastric emptying, though, is still controversial; while some authors found an improvement [47,53], others found no difference between HPFs and SPFs [54].

Extensively HPFs (eHPFs) have been shown to improve GOR features in term infants and children symptomatic for GOR [55]. Sensitized infants with cow's milk allergy (CMA) are known to develop gastric dysrhythmia, which can lead to a severe impairment of gastric motor function and delayed gastric emptying, thereby contributing to GOR exacerbation [56, 57]. For this reason, infants with CMA are more likely to suffer from symptoms as regurgitation and vomiting, which appear to be indistinguishable from physiological GOR. Thus, when own mother's milk is not available, the dietary management of GOR recommended in the recent guidelines by the European Society of Pediatric Gastroenterology, Hepatology, and Nutrition includes a 2-4week trial of eHPF or amino acid based formula [20].

In a recent trial, we have compared the efficacy of an eHPF versus a SPF on GOR features in preterm infants symptomatic for both GOR and feeding intolerance. A significant decrease 
in total acid GOR episodes and reflux index was observed in newborns fed the eHPF, whereas no difference between the two formulas was found in terms of GOR height and nonacid GOR features [58]. Acid GORs being more frequent in the late postprandial period, the reduction in acid GOR could be attributed to the enhancement of gastric emptying previously reported in premature infants fed eHPFs [47]. This is the first study aiming to evaluate the efficacy of eHPFs on GOR features in preterm infants. According to our preliminary findings, eHPFs are effective in decreasing acid GOR in preterm infants experiencing symptoms of GOR and feeding intolerance. However, the sample size was small, leading to a low power to evaluate the clinical efficacy of the eHPF on GOR symptoms. Furthermore, it should be considered that the nutritional characteristics of the majority of eHPFs are generally inadequate for the high nutritional needs of preterm infants. Therefore, further larger trials should be carried out to confirm the efficacy of a nutritionally adequate eHPF in reducing acid GOR features and improving GOR clinical symptoms in the preterm population.

\section{Human Milk Fortifiers and Human Milk Protein Content}

In order to achieve the nutritional needs of preterm infants, human milk is usually supplemented with commercial human milk fortifiers (HMFs), which contain proteins, carbohydrates, and minerals. As stated in a systematic review [59], preterm infants fed fortified HM have improved weight gain, linear growth, and head circumference growth without experiencing major adverse effects (i.e., necrotising enterocolitis). On the other hand, HM fortification might lead to feeding intolerance, because it increases osmolality to values higher than the expected, with further increase over time [60]. Moreover, a worsening of acid GOR related to an increase in the osmolality of meals has been previously demonstrated in infants and children [61].

We have previously evaluated whether standard fortification with different amounts of HMFs (the low dose being 3\% and the higher 5\%) may affect GOR features in symptomatic preterm infants [62]. The standard addition of both HMF 3\% and HMF 5\% led to a significant increase of nonacid GORs, nonacid reflux index, and oesophageal height of reflux, while no difference was observed in acid GOR features.

So far, this is the first study to explore the effect of HMFs on GOR features in preterm infants; therefore, these preliminary data, obtained from a relatively small population, need to be validated in larger clinical trials.

\section{Intragastric Tubes}

Due to the inability of preterm infants to coordinate sucking, swallowing, and breathing, tube feeding is frequently used in NICUs. However, the presence of a tube through the gastroesophageal junction can exacerbate GOR through two different mechanisms: firstly, weakening the competence of
LOS and subsequently enhancing the refluxate of gastric content into the oesophageal lumen [63] and, secondly, impairing oesophageal clearance [64]. Consistently with this assumption, Peter et al. [32] found a higher incidence of GOR, especially after the first postprandial hour, in a small cohort of preterm infants who had the MII catheter placed through the gastroesophageal junction. A similar study, evaluating the impact of two different nasogastric tubes on GOR in term neonates and older infants, found no effect with the smaller tube $(8 \mathrm{~F})$ but an increase of GOR in association with the larger one (12 F) [64]. Conversely, two trials [35, 65] evaluating tube versus oral feeding in symptomatic term and preterm infants found a significantly lower rate of GORs in the tube-fed group; this opposite result might be due to some methodological differences between the studies such as, for instance, the tube size or the removal of the feeding tube during the postprandial period. To avoid potential effects related to the presence of an intragastric tube in infants with GOR unable to bottle-feed, the withdrawal of the feeding tube after bolus administration might represent a feasible strategy [32]; however, before being recommended, this practice should be tested in a larger, randomized trial, in order to weigh the potential advantages against side effects (i.e., oesophageal irritation).

\section{Pacifier Usage}

Nonnutritive sucking (NNS) influences gastrointestinal functions of preterm infants, increasing the sucking reflex maturation and endorsing an earlier achievement of full oral feeding [66]; moreover, NNS is reported to slow down the intestinal transit time and to enhance weight gain [67], while no effects were observed on gastric emptying and nutrient absorption [68, 69]. A higher number of swallows are observed during NNS. It has been previously documented that swallowing elicits LOS relaxation, which is known to exacerbate the rise of gastric content into the oesophagus [70]. At the same time, however, the act of swallowing seems to promote the oesophageal clearance of refluxate [71]; therefore, a possible role of NNS on gastroesophageal reflux might be hypothesized.

The first study evaluating the role of NNS on GOR was performed by Orenstein in 1988. Term infants younger than 6 months using a pacifier underwent $\mathrm{pH}$ monitoring [72]; NNS was reported to influence only the frequency of GOR episodes, which was increased in the prone position and decreased in the seated position. This controversial finding, however, cannot be applied to premature babies.

So far, the efficacy of NNS by means of a pacifier on preterm infants with symptomatic GOR has been investigated only by Zhao et al. [73], who reported a faster gastric emptying as well as a reduction of GOR features (number of refluxes, reflux index, and total time at $\mathrm{pH}<4$ ) in infants receiving NNS; however, as GOR episodes were detected by a $\mathrm{pH}$ probe, the effect of NNS on nonacid GOR was not evaluated. Thus, further studies are needed to clarify the role of pacifier usage in preterm infants with pathologic GOR. 


\section{Conclusions}

Gastroesophageal reflux is a common and mainly physiological condition in preterm infants. Although evidence currently available on the conservative management of GOR is still limited, a stepwise approach, with nonpharmacological strategies as the first-line treatment, is advisable in infants experiencing noncomplicated GOR. On the basis of the existing literature, body positioning can be considered the most established and safe treatment. Left-side and prone positions are effective in reducing both acid and nonacid GORs but should be limited to hospitalized preterm infants due to the higher risks of SIDS. Improvements can also be obtained by dietary changes; particularly, a prolonged feeding duration seems to be effective in infants with predominant nonacid GOR, whereas symptomatic babies with acid GOR might benefit from frequent, small feeds. Extensively hydrolysed formulas are found to improve acid GOR features, while both formula and human milk thickening resulted to be ineffective and potentially harmful. Finally, the role of nonnutritive sucking and intragastric tubes is still controversial, thereby needing to be further investigated in larger trials.

\section{References}

[1] A. S. Dhillon and A. K. Ewer, "Diagnosis and management of gastro-oesophageal reflux in preterm infants in neonatal intensive care units," Acta Paediatrica, vol. 93, no. 1, pp. 88-93, 2004.

[2] T. I. Omari, C. P. Barnett, M. A. Benninga et al., "Mechanisms of gastro-oesophageal reflux in preterm and term infants with reflux disease," Gut, vol. 51, no. 4, pp. 475-479, 2002.

[3] J. L. Birch and S. J. Newell, "Gastrooesophageal reflux disease in preterm infants: current management and diagnostic dilemmas," Archives of Disease in Childhood, vol. 94, no. 5, pp. F379F383, 2009.

[4] G. Frakaloss, G. Burke, and M. R. Sanders, "Impact of gastroesophageal reflux on growth and hospital stay in premature infants," Journal of Pediatric Gastroenterology and Nutrition, vol. 26, no. 2, pp. 146-150, 1998.

[5] C. F. Poets, "Gastroesophageal reflux: a critical review of its role in preterm infants," Pediatrics, vol. 113, no. 2, pp. e128-e132, 2004.

[6] S. Farhath, Z. He, T. Nakhla et al., "Pepsin, a marker of gastric contents, is increased in tracheal aspirates from preterm infants who develop bronchopulmonary dysplasia," Pediatrics, vol. 121, no. 2, pp. e253-e259, 2008.

[7] E. Akinola, T. S. Rosenkrantz, M. Pappagallo, K. McKay, and N. Hussain, "Gastroesophageal reflux in infants $<32$ weeks gestational age at birth: lack of relationship to chronic lung disease," American Journal of Perinatology, vol. 21, no. 2, pp. 5762, 2004.

[8] S. Farhath, Z. He, J. Saslow et al., "Detection of pepsin in mouth swab: correlation with clinical gastroesophageal reflux in preterm infants," Journal of Maternal-Fetal and Neonatal Medicine, vol. 26, no. 8, pp. 819-824, 2013.

[9] P. Schurr and C. K. Findlater, "Neonatal mythbusters: evaluating the evidence for and against pharmacologic and nonpharmacologic management of gastroesophageal reflux," Neonatal Network, vol. 31, no. 4, pp. 229-241, 2012.
[10] J. R. Lightdale and D. A. Gremse, "Section on Gastroenterology $\mathrm{Hp}$, and Nutrition. Gastroesophageal reflux: management guidance for the pediatrician," Pediatrics, vol. 131, no. 5, pp. e1684e1695, 2013.

[11] W. F. Malcolm, M. Gantz, R. J. Martin, R. F. Goldstein, R. N. Goldberg, and C. M. Cotten, "Use of medications for gastroesophageal reflux at discharge among extremely low birth weight infants," Pediatrics, vol. 121, no. 1, pp. 22-27, 2008.

[12] R. Guillet, B. J. Stoll, C. M. Cotten et al., "Association of H2blocker therapy and higher incidence of necrotizing enterocolitis in very low birth weight infants," Pediatrics, vol. 117, no. 2, pp. e137-e142, 2006.

[13] K. More, G. Athalye-Jape, S. Rao, and S. Patole, "Association of inhibitors of gastric acid secretion and higher incidence of necrotizing enterocolitis in preterm very low-birth-weight infants," American Journal of Perinatology. In press.

[14] G. Terrin, A. Passariello, M. De Curtis et al., "Ranitidine is associated with infections, necrotizing enterocolitis, and fatal outcome in newborns," Pediatrics, vol. 129, no. 1, pp. e40-e45, 2012.

[15] A. Dubin, M. Kikkert, M. Mirmiran, and R. Ariagno, "Cisapride associated with QTc prolongation in very low birth weight preterm infants," Pediatrics, vol. 107, no. 6, pp. 1313-1316, 2001.

[16] L. Corvaglia, G. Faldella, R. Rotatori, M. Lanari, M. G. Capretti, and G. P. Salvioli, "Intrauterine growth retardation is a risk factor for Cisapride-induced QT prolongation in preterm infants," Cardiovascular Drugs and Therapy, vol. 18, no. 5, pp. 371-375, 2004.

[17] L. Corvaglia, E. Mariani, A. Aceti, M. G. Capretti, G. Ancora, and G. Faldella, "Combined oesophageal impedance-pH monitoring in preterm newborn: comparison of two options for layout analysis," Neurogastroenterology and Motility, vol. 21, no. 10, pp. e1027-e1081, 2009.

[18] L. Corvaglia, D. Zama, M. Spizzichino et al., "The frequency of apneas in very preterm infants is increased after non-acid gastro-esophageal reflux," Neurogastroenterology and Motility, vol. 23, no. 4, pp. 303-307, 2011.

[19] R. J. van der Pol, M. J. Smits, L. Venmans, N. Boluyt, M. A. Benninga, and M. M. Tabbers, "Diagnostic accuracy of tests in pediatric gastroesophageal reflux disease," Journal of Pediatrics, vol. 162, no. 5, pp. 983-987, 2013.

[20] Y. Vandenplas, C. D. Rudolph, C. Di Lorenzo et al., "Pediatric gastroesophageal reflux clinical practice guidelines: joint recommendations of the North American Society for Pediatric Gastroenterology, Hepatology, and Nutrition (NASPGHAN) and the European Society for Pediatric Gastroenterology, Hepatology, and Nutrition (ESPGHAN)," Journal of Pediatric Gastroenterology and Nutrition, vol. 49, no. 4, pp. 498-547, 2009.

[21] I. Blumenthal and G. T. Lealman, "Effect of posture on gastrooesophageal reflux in the newborn," Archives of Disease in Childhood, vol. 57, no. 7, pp. 555-556, 1982.

[22] A. K. Ewer, M. E. James, and J. M. Tobin, "Prone and left lateral positioning reduce gastro-oesophageal reflux in preterm infants," Archives of Disease in Childhood, vol. 81, no. 3, pp. F201F205, 1999.

[23] R. Y. Bhat, G. F. Rafferty, S. Hannam, and A. Greenough, "Acid gastroesophageal reflux in convalescent preterm infants: effect of posture and relationship to apnea," Pediatric Research, vol. 62, no. 5, pp. 620-623, 2007.

[24] T. I. Omari, N. Rommel, E. Staunton et al., "Paradoxical impact of body positioning on gastroesophageal reflux and gastric 
emptying in the premature neonate," Journal of Pediatrics, vol. 145, no. 2, pp. 194-200, 2004.

[25] M. P. van Wijk, M. A. Benninga, J. Dent et al., "Effect of body position changes on postprandial gastroesophageal reflux and gastric emptying in the healthy premature neonate," Journal of Pediatrics, vol. 151, no. 6, pp. 585-590, 2007.

[26] L. Corvaglia, R. Rotatori, M. Ferlini, A. Aceti, G. Ancora, and G. Faldella, "The effect of body positioning on gastroesophageal reflux in premature infants: evaluation by combined impedance and pH monitoring," Journal of Pediatrics, vol. 151, no. 6, pp. 591596, 2007.

[27] R. Y. Moon, R. A. Darnall, M. H. Goodstein et al., "SIDS and other sleep-related infant deaths: expansion of recommendations for a safe infant sleeping environment," Pediatrics, vol. 128, no. 5, pp. 1030-1039, 2011.

[28] S. R. Orenstein, "Prone positioning in infant gastroesophageal reflux: is elevation of the head worth the trouble?" Journal of Pediatrics, vol. 117, no. 2, part 1, pp. 184-187, 1990.

[29] B. Bagucka, J. De Schepper, M. Peelman, K. Van De Maele, and Y. Vandenplas, "Acid gastro-esophageal reflux in the $10^{\circ}$ reversed-Trendelenburg-position in supine sleeping infants," Acta Paediatrica Taiwanica, vol. 40, no. 5, pp. 298-301, 1999.

[30] S. R. Orenstein, P. F. Whitington, and D. M. Orenstein, "The infant seat as treatment for gastroesophageal reflux," New England Journal of Medicine, vol. 309, no. 13, pp. 760-763, 1983.

[31] D. Sifrim, D. Castell, J. Dent, and P. J. Kahrilas, "Gastrooesophageal reflux monitoring: review and consensus report on detection and definitions of acid, non-acid, and gas reflux," Gut, vol. 53, no. 7, pp. 1024-1031, 2004.

[32] C. S. Peter, C. Wiechers, B. Bohnhorst, J. Silny, and C. F. Poets, "Influence of nasogastric tubes on gastroesophageal reflux in preterm infants: a multiple intraluminal impedance study," Journal of Pediatrics, vol. 141, no. 2, pp. 277-279, 2002.

[33] R. H. Holloway, M. Hongo, K. Berger, and R. W. McCallum, "Gastric distention: a mechanism for postprandial gastroesophageal reflux," Gastroenterology, vol. 89, no. 4, pp. 779-784, 1985.

[34] T. E. Bowling, B. Cliff, J. W. Wright, P. E. Blackshaw, A. C. Perkins, and D. N. Lobo, "The effects of bolus and continuous nasogastric feeding on gastro-oesophageal reflux and gastric emptying in healthy volunteers: a randomised three-way crossover pilot study," Clinical Nutrition, vol. 27, no. 4, pp. 608613, 2008.

[35] S. R. Jadcherla, C. Y. Chan, R. Moore, M. Malkar, C. J. Timan, and C. J. Valentine, "Impact of feeding strategies on the frequency and clearance of acid and nonacid gastroesophageal reflux events in dysphagic neonates," Journal of Parenteral and Enteral Nutrition, vol. 36, no. 4, pp. 449-455, 2012.

[36] A. Horvath, P. Dziechciarz, and H. Szajewska, "The effect of thickened-feed interventions on gastroesophageal reflux in infants: systematic review and meta-analysis of randomized, controlled trials," Pediatrics, vol. 122, no. 6, pp. e1268-e1277, 2008.

[37] I. Xinias, N. Mouane, B. Le Luyer et al., "Cornstarch thickened formula reduces oesophageal acid exposure time in infants," Digestive and Liver Disease, vol. 37, no. 1, pp. 23-27, 2005.

[38] T. G. Wenzl, S. Schneider, F. Scheele, J. Silny, G. Heimann, and H. Skopnik, "Effects of thickened feeding on gastroesophageal reflux in infants: a placebo-controlled crossover study using intraluminal impedance," Pediatrics, vol. 111, no. 4, part 1, pp. e355-e359, 2003.
[39] S. R. Orenstein, T. M. Shalaby, and P. E. Putnam, “Thickened feedings as a cause of increased coughing when used as therapy for gastroesophageal reflux in infants," Journal of Pediatrics, vol. 121, no. 6, pp. 913-915, 1992.

[40] F. Savino, M. C. Muratore, L. Silvestro, R. Oggero, and M. Mostert, "Allergy to carob gum in an infant," Journal of Pediatric Gastroenterology and Nutrition, vol. 29, no. 4, pp. 475-476, 1999.

[41] E. Levtchenko, B. Hauser, and Y. Vandenplas, "Nutritional value of an "anti-regurgitation" formula," Acta Gastro-Enterologica Belgica, vol. 61, no. 3, pp. 285-287, 1998.

[42] D. Bosscher, M. Van Caillie-Bertrand, K. Van Dyck, H. Robberecht, R. Van Cauwenbergh, and H. Deelstra, "Thickening infant formula with digestible and indigestible carbohydrate: availability of calcium, iron, and zinc in vitro," Journal of Pediatric Gastroenterology and Nutrition, vol. 30, no. 4, pp. 373378, 2000.

[43] L. Corvaglia, M. Ferlini, R. Rotatori et al., "Starch thickening of human milk is ineffective in reducing the gastroesophageal reflux in preterm infants: a crossover study using intraluminal impedance," Journal of Pediatrics, vol. 148, no. 2, pp. 265-268, 2006.

[44] P. Clarke and M. J. Robinson, “Thickening milk feeds may cause necrotising enterocolitis," Archives of Disease in Childhood, vol. 89, no. 3, p. F280, 2004.

[45] J. Beal, B. Silverman, J. Bellant, T. E. Young, and K. Klontz, "Late onset necrotizing enterocolitis in infants following use of a xanthan gum-containing thickening agent," Journal of Pediatrics, vol. 161, no. 2, pp. 354-356, 2012.

[46] L. Corvaglia, A. Aceti, E. Mariani et al., "Lack of efficacy of a starch-thickened preterm formula on gastro-oesophageal reflux in preterm infants: a pilot study," Journal of Maternal-Fetal and Neonatal Medicine, vol. 25, no. 12, pp. 2735-2738, 2012.

[47] W. A. Mihatsch, J. Högel, and F. Pohlandt, "Hydrolysed protein accelerates the gastrointestinal transport of formula in preterm infants," Acta Paediatrica, vol. 90, no. 2, pp. 196-198, 2001.

[48] J. S. Hyams, W. R. Treem, N. L. Etienne et al., "Effect of infant formula on stool characteristics of young infants," Pediatrics, vol. 95, no. 1, pp. 50-54, 1995.

[49] W. A. Mihatsch, A. R. Franz, J. Högel, and F. Pohland, "Hydrolyzed protein accelerates feeding advancement in very low birth weight infants," Pediatrics, vol. 110, no. 6, pp. 11991203, 2002.

[50] A. A. Zuppa, F. Visintini, F. Cota, L. Maggio, C. Romagnoli, and G. Tortorolo, "Hydrolysed milk in preterm infants: an open problem," Acta Paediatrica, Supplement, vol. 94, no. 449, pp. 8486, 2005.

[51] R. Tormo, N. Potau, D. Infante, J. Moran, B. Martin, and A. Bergada, "Protein in infant formulas: future aspects of development," Early Human Development, vol. 53, supplement, pp. S165-S172, 1998.

[52] W. A. Mihatsch, A. R. Franz, B. Kuhnt, J. Högel, and F. Pohlandt, "Hydrolysis of casein accelerates gastrointestinal transit via reduction of opioid receptor agonists released from casein in rats," Biology of the Neonate, vol. 87, no. 3, pp. 160-163, 2005.

[53] V. Tolia, C.-H. Lin, and L. R. Kuhns, "Gastric emptying using three different formulas in infants with gastroesophageal reflux," Journal of Pediatric Gastroenterology and Nutrition, vol. 15, no. 3, pp. 297-301, 1992.

[54] G. Riezzo, F. Indrio, O. Montagna et al., "Gastric electrical activity and gastric emptying in preterm newborns fed standard and hydrolysate formulas," Journal of Pediatric Gastroenterology and Nutrition, vol. 33, no. 3, pp. 290-295, 2001. 
[55] A. Garzi, M. Messina, F. Frati et al., "An extensively hydrolysed cow's milk formula improves clinical symptoms of gastroesophageal reflux and reduces the gastric emptying time in infants," Allergologia et Immunopathologia, vol. 30, no. 1, pp. 3641, 2002.

[56] S. Salvatore and Y. Vandenplas, "Gastroesophageal reflux and cow milk allergy: is there a link?” Pediatrics, vol. 110, no. 5, pp. 972-984, 2002.

[57] A. M. Ravelli, P. Tobanelli, S. Volpi, and A. G. Ugazio, "Vomiting and gastric motility in infants with cow's milk allergy," Journal of Pediatric Gastroenterology and Nutrition, vol. 32, no. 1, pp. 5964, 2001.

[58] L. Corvaglia, E. Mariani, A. Aceti, S. Galletti, and G. Faldella, "Extensively hydrolyzed protein formula reduces acid gastroesophageal reflux in symptomatic preterm infants," Early Human Development, vol. 89, no. 7, pp. 453-455, 2013.

[59] C. A. Kuschel and J. E. Harding, "Multicomponent fortified human milk for promoting growth in preterm infants," Cochrane Database of Systematic Reviews, no. 1, Article ID CD000343, 2004.

[60] M. De Curtis, M. Candusso, C. Pieltain, and J. Rigo, "Effect of fortification on the osmolality of human milk," Archives of Disease in Childhood, vol. 81, no. 2, pp. F141-F143, 1999.

[61] G. Salvia, B. De Vizia, F. Manguso et al., "Effect of intragastric volume and osmolality on mechanisms of gastroesophageal reflux in children with gastroesophageal reflux disease," American Journal of Gastroenterology, vol. 96, no. 6, pp. 1725-1732, 2001.

[62] A. Aceti, L. Corvaglia, V. Paoletti et al., "Protein content and fortification of human milk influence gastroesophageal reflux in preterm infants," Journal of Pediatric Gastroenterology and Nutrition, vol. 49, no. 5, pp. 613-618, 2009.

[63] I. E. Vinnik and F. Kern Jr., "The effect of gastric intubation on esophageal PH," Gastroenterology, vol. 47, pp. 388-394, 1964.

[64] N. Noviski, Y. Yehuda Ben, F. Serour, A. Gorenstein, and A. Mandelberg, "Does the size of nasogastric tubes affect gastroesophageal reflux in children?" Journal of Pediatric Gastroenterology and Nutrition, vol. 29, no. 4, pp. 448-451, 1999.

[65] T. Abe, Y. Hata, F. Sasaki, J. Uchino, K. Aoyama, and H. Nannbu, "The effect of tube feeding on postprandial gastroesophageal reflux," Journal of Pediatric Surgery, vol. 28, no. 1, pp. 56-58, 1993.

[66] J. Pinelli and A. Symington, "Non-nutritive sucking for promoting physiologic stability and nutrition in preterm infants," Cochrane Database of Systematic Reviews, no. 4, Article ID CD001071, 2005.

[67] J. C. Bernbaum, G. R. Pereira, J. B. Watkins, and G. J. Peckham, "Nonnutritive sucking during gavage feeding enhances growth and maturation in premature infants," Pediatrics, vol. 71, no. 1, pp. 41-45, 1983.

[68] J. S. Szabo, A. C. Hillemeier, and W. Oh, "Effect of non-nutritive and nutritive suck on gastric emptying in premature infants," Journal of Pediatric Gastroenterology and Nutrition, vol. 4, no. 3, pp. 348-351, 1985.

[69] M. De Curtis, N. McIntosh, V. Ventura, and O. Brooke, "Effect of nonnutritive sucking on nutrient retention in preterm infants," Journal of Pediatrics, vol. 109, no. 5, pp. 888-890, 1986.

[70] G. E. Boeckxstaens, "The lower oesophageal sphincter," Neurogastroenterology and Motility, vol. 17, no. 1, pp. 13-21, 2005.

[71] R. M. Bremner, S. F. Hoeft, M. Costantin et al., "Pharyngeal swallowing: the major factor in clearance of esophageal reflux episodes," Annals of Surgery, vol. 218, no. 3, pp. 364-370, 1993.
[72] S. R. Orenstein, "Effect of nonnutritive sucking on infant gastroesophageal reflux," Pediatric Research, vol. 24, no. 1, pp. 38-40, 1988.

[73] C.-X. Zhao, X.-H. Yue, H. Lu, and X.-D. Xue, "Effects of nonnutritive sucking on gastric emptying and gastroesophageal reflux in premature infants," Chinese Journal of Pediatrics, vol. 42, no. 10, pp. 772-776, 2004. 


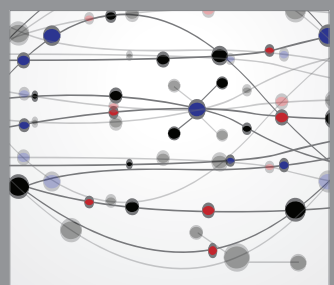

The Scientific World Journal
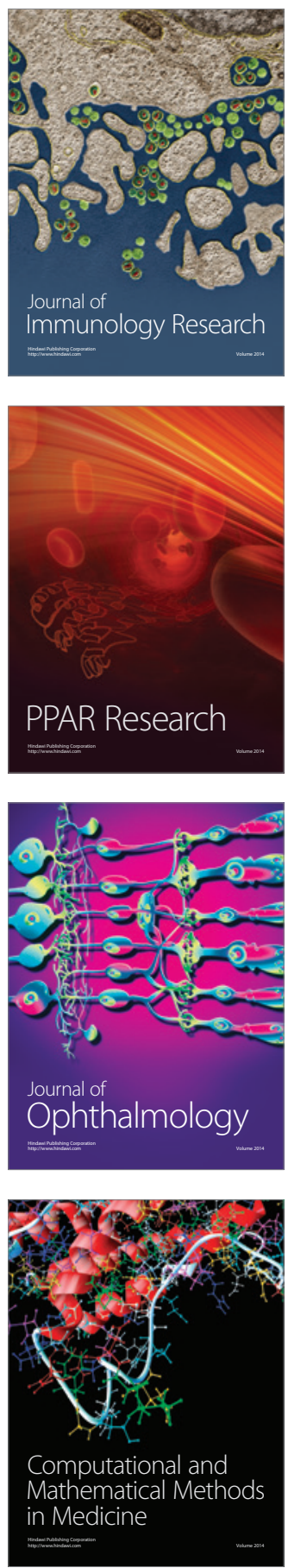

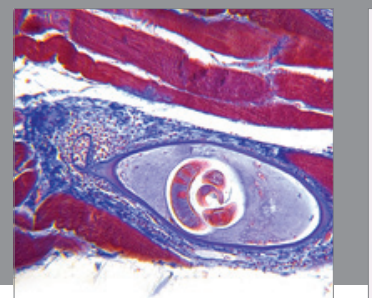

Gastroenterology

Research and Practice
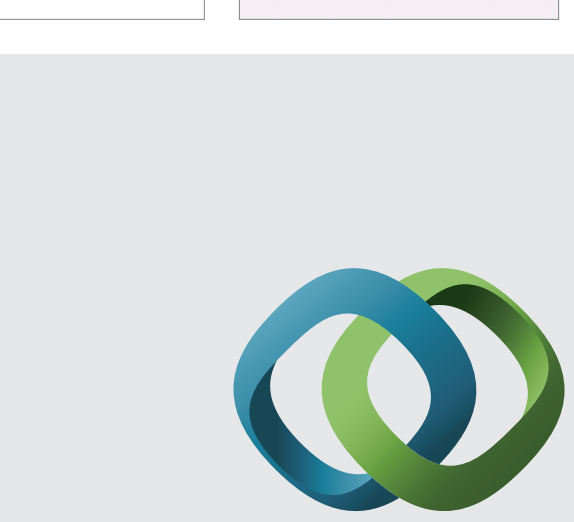

\section{Hindawi}

Submit your manuscripts at

http://www.hindawi.com
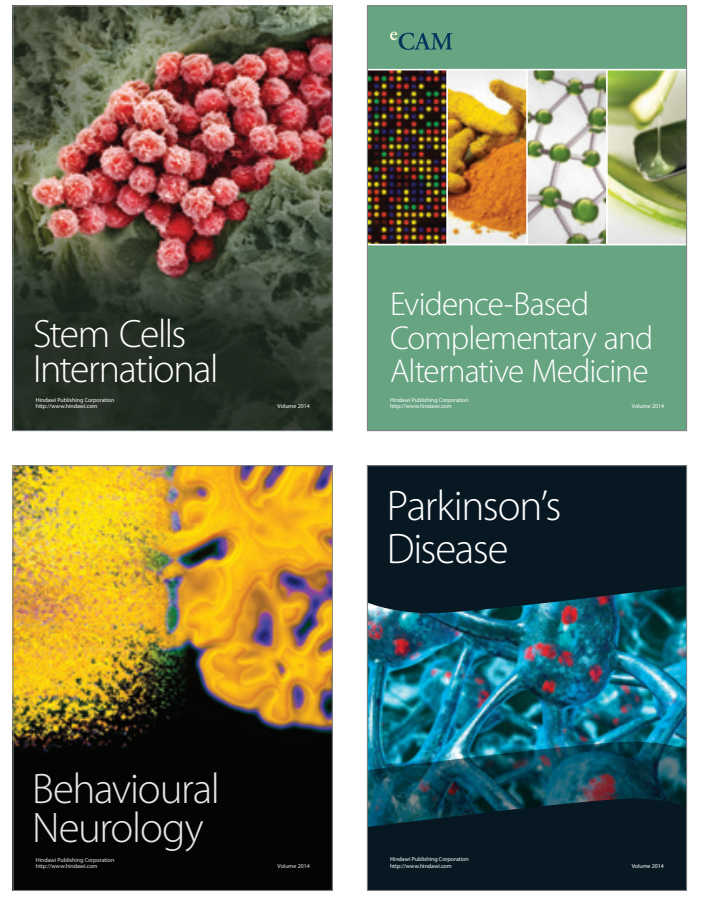
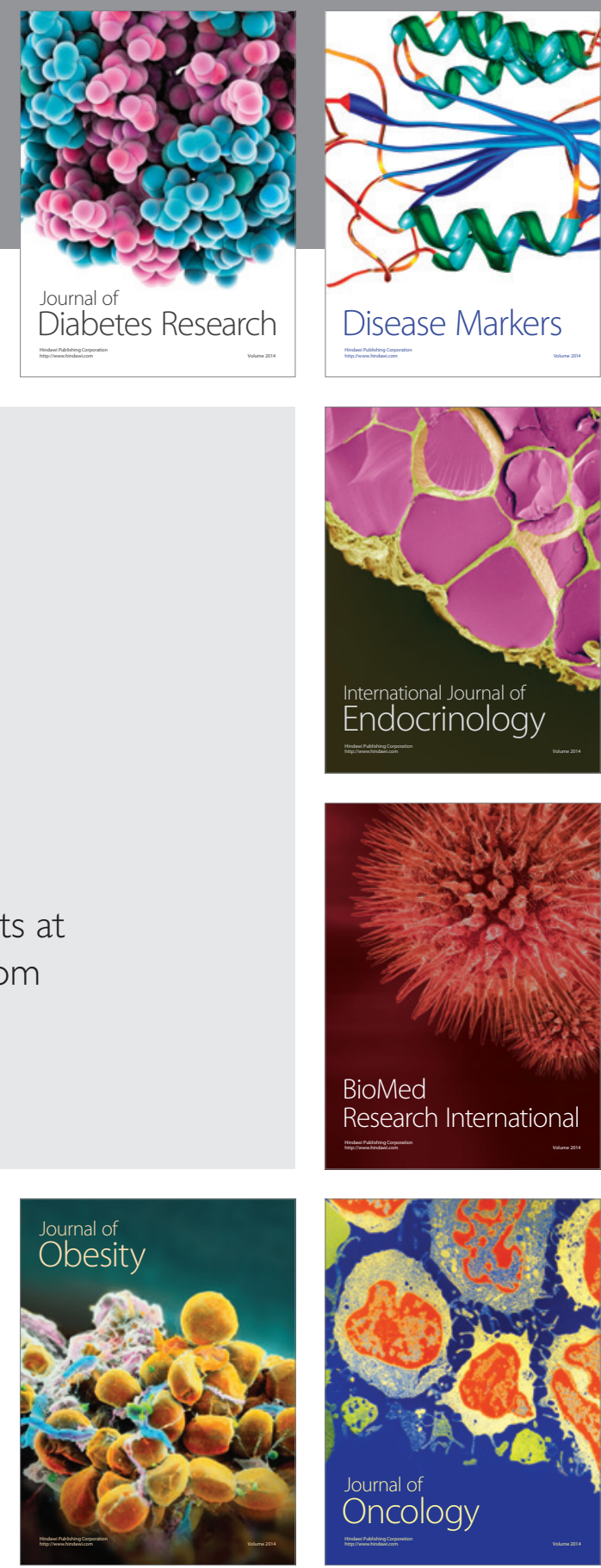

Disease Markers
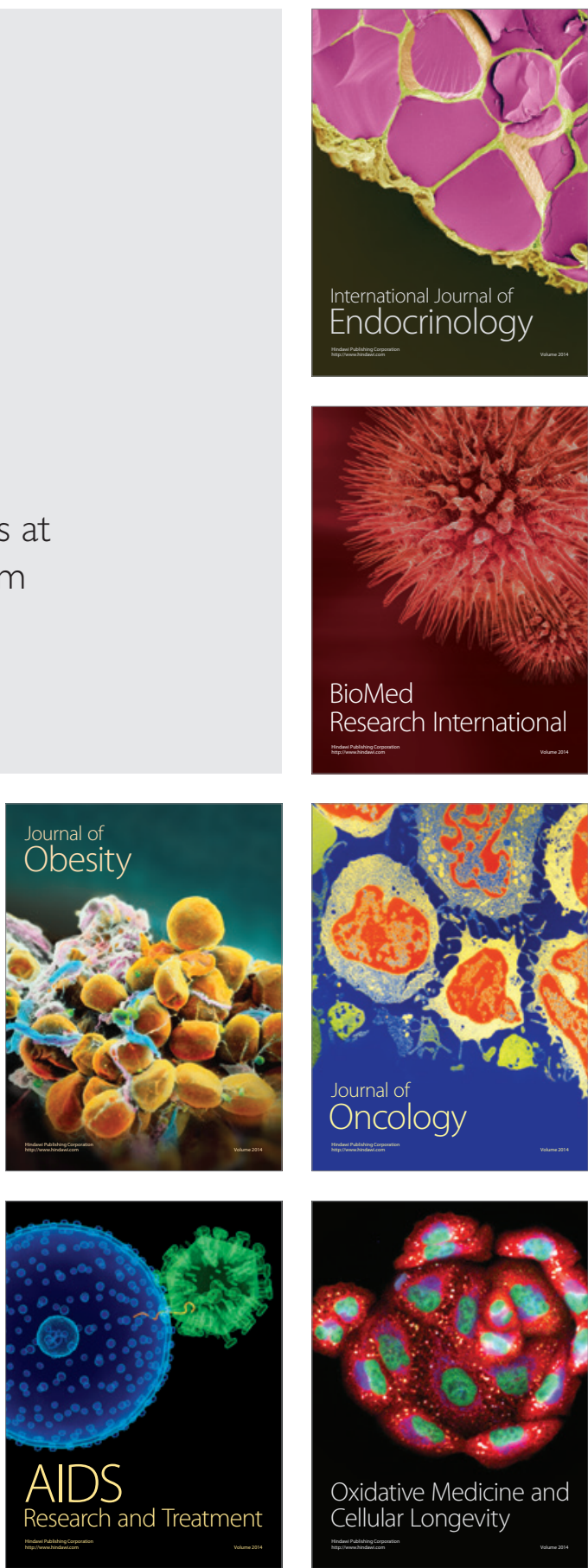